\title{
Diurnal responses of photosynthesis and fluorescence in Ulva rotundata acclimated to sun and shade in outdoor culture
}

\author{
William J. Henley ${ }^{1, *}$, Guy Levavasseur ${ }^{1,2}$, Linda A. Franklin ${ }^{1,3}$, Steven T. Lindley ${ }^{1,3}$, \\ J. Ramus ${ }^{1,3}$, C. Barry Osmond ${ }^{3}$ \\ ${ }^{1}$ Duke University Marine Laboratory, Beaufort, North Carolina 28516, USA \\ ${ }^{2}$ Station Biologique, CNRS and Université Paris VI, F-29680, Roscoff, France \\ ${ }^{3}$ Department of Botany, Duke University, Durham, North Carolina 27706, USA
}

\begin{abstract}
Thalli of the chlorophyte macroalga Ulva rotundata were acclimated to sun $\left(100 \% I_{0}\right)$ and shade $\left(9 \% I_{0}\right)$ in outdoor tumble tanks under nutrient-sufficient conditions. Diurnal patterns were determined for areal photosynthetic $\mathrm{O}_{2}$ exchange capacity $\left(P_{\mathrm{m}}\right)$ and quantum yield $(\phi)$, respiration $\left(R_{\mathrm{d}}\right)$, and photosystem (PS) II chlorophyll fluorescence using 2 independent techniques. Net $P_{\mathrm{m}}$ was maximal at midday in sun-grown thalli and at midmorning in shade-grown thalli exposed to $100 \% I_{0}$. A slight afternoon decline in net $P_{\mathrm{m}}$ in shade-grown thalli exposed to $100 \% I_{0}$ could be explained entirely by a concurrent rise in $R_{\mathrm{d}}$. Sun thalli exhibited a larger diurnal fluctuation of net $P_{\mathrm{m}}$ which was inconsistent with photoinhibition or end product inhibition by accumulated photosynthate. This leaves endogenous control as the most likely cause, with slight modification by $R_{\mathrm{d}}$. Fluorescence data were consistent with simultaneous damage to PSII and photoprotection by thermal deexcitation, with sun thalli showing greater capacity for protection. Both of these processes reduced $\phi$ but apparently did not affect $P_{\mathrm{m}}$. In that $U$. rotundata thalli were light-saturated in our tumble tanks for most of the day, we conclude that photoinhibition (三 damage + protection) had little effect on integrated diumal production under these conditions. Our results demonstrate the utility of fluorescence analysis and the importance of precise determination of $P_{\mathrm{m}}, \phi$ and $R_{\mathrm{d}}$ in ascribing mechanisms to diurnal fluctuations in photosynthetic performance. The validity of using photosynthetic light-response (P-I) curves determined at one time of day to predict integrated diurnal production will depend on the extent to which $P_{\mathrm{m}} \phi$ and $R_{\mathrm{d}}$ vary. This in turn depends on species, irradiance history, and possibly other factors such as temperature and nutrition
\end{abstract}

\section{INTRODUCTION}

It has long been observed that photosynthetic performance of aquatic macrophytes often peaks at or before midday, and exhibits either a temporary midday depression or a sustained afternoon decline (Ramus \& Rosenberg 1980, Coutinho \& Zingmark 1987). However, little is known regarding the cause(s) of this pattern. Some reports implicated an endogenous rhythm (Britz \& Briggs 1976, Okada et al. 1978, Titlyanov et al. 1978, Mishkind et al. 1979, Oohusa 1980, Levavasseur \& Giraud 1982), whereas others did not

\footnotetext{
- Present address, for reprints and correspondence: Marine Science Institute, University of Texas at Austin, Port Aransas, Texas 78373-1267, USA
}

find evidence for this (Blinks \& Givan 1961, McCracken et al. 1975, Huppertz et al. 1990). Feedback regulation by accumulated carbohydrate also has been suggested (Meyer 1939, Levavasseur \& Giraud 1982), although definitive data are lacking. In phytoplankton, photorespiration or photoinhibition - the direct impairment of photosynthetic electron transport by supersaturating irradiance - is often invoked to explain midday photosynthetic depression (reviewed by Harris \& Piccinin 1977. Neale 1987). Although photoinhibition sometimes is claimed to occur in macrophytes (e.g. Huppertz et al. 1990), at least 2 studies suggested that photoinhibition per se is not involved in midday depression (McCracken et al. 1975, Titlyanov et al. 1978).

It is likely that photoinhibition, a light-dependent decrease in photosynthetic efficiency, involves either 
or both of 2 processes: photodamage to the photosystem II (PSII) reaction center complex and photoprotection via thermal deexcitation (reviewed by Critchley 1988, Krause 1988, Demmig-Adams 1990). Insofar as both may occur simultaneously and exhibit some common symptoms, it is unclear whether they may be resolved at present (Chow et al. 1989, Demmig-Adams 1990). We have made detailed laboratory studies of photoinhibitory phenomena in Ulva rotundata transferred from low to high light, which gave results consistent with both events, with photodamage predominating under $\mathrm{N}$-deficient conditions (Henley et al. 1991). This report evaluates the significance of photoinhibition in this species under natural, diurnally varying irradiance conditions in nutrient-enriched outdoor tumble tanks.

\section{MATERIALS AND METHODS}

Experimental conditions. Vegetative tissue of Ulva rotundata (clone 786 ) from the vicinity of Beaufort, North Carolina, USA, was grown in sparged outdoor continuous-flow tanks enriched with $\mathrm{N}$ and $\mathrm{P}$ (Henley \& Ramus 1989a). Thalli were conditioned for $>2 \mathrm{wk}$ in tanks which were either unscreened $\left(100 \% \quad I_{0}\right)$ or covered with 4 nylon window screens $\left(9 \% I_{0}\right)$. Measurements of fluorescence and light response curves for photosynthesis were performed using samples taken directly from the tanks at ca $45 \mathrm{~min}$ intervals from dawn to dusk. The screens were removed from the $9 \% I_{0}$ tank at dawn on the day of measurement, exposing them to $100 \% I_{0}$ for the entire day. Diurnal measurements were conducted on 2 consecutive days both in April $\left(100 \% I_{0}\right.$ thalli) and in May 1990 ( $9 \% I_{0}$ thalli). On 18 September 1990 , diurnal measurements were performed using thalli grown at $100 \% I_{0}$ and shaded to $9 \% I_{0}$ for the entire day. Irradiance (400 to $700 \mathrm{~nm})$ was measured at each sampling time using a spherical quantum sensor (Model LI-193SA; Li-Cor, Lincoln, NE, USA) which was submersed in a tank lacking seaweeds. Mean seawater temperatures on the 5 experimental dates ranged from about 21 to $24^{\circ} \mathrm{C}$, and intraday ranges were 2 to $3^{\circ} \mathrm{C}$.

Photosynthetic measurements. Photosynthetic $\mathrm{O}_{2}$ exchange was measured at 18,20 or $24^{\circ} \mathrm{C}$, depending on ambient seawater temperature, in a customized water-jacketed acrylic chamber $(18 \mathrm{ml})$, using a polarographic electrode and computer-interfaced control circuit (Model CB1-D/IF-1; Hansatech, Kings Lynn, Norfolk, UK), as described by Henley et al. (1991). Light was provided by a computer-controlled red (maximum ca $650 \mathrm{~nm}$ ) light-emitting diode array (Model LS3/LH36U; Hansatech), and measured directly behind the sample chamber with a cosine-corrected sensor (Model LI-192SA; Li-Cor). Thallus absorptance, used to calculate quantum yield $(\phi)$ from the initial slopes of photosynthetic light response (P-I) curves, was estimated from irradiance measurements with and without the sample present.

Square samples $(2 \times 2 \mathrm{~cm})$ of Ulva rotundata thallus were cut, rinsed, and inserted in a nylon mesh frame normal to the light path in the sample chamber containing filtered, $\mathrm{N}_{2}$-sparged seawater $\left(\mathrm{O}_{2}\right.$ concentration of about $40 \%$ saturation). After $5 \mathrm{~min}$ equilibration in darkness, the tissue was exposed to a series of 17 programmed incremental irradiances, and data were continuously monitored and $\mathrm{O}_{2}$ exchange rates calculated in real time using a microcomputer program. Total exposure time at each irradiance was $2 \mathrm{~min}$, and rates were determined over the last $90 \mathrm{~s}$. The final $\mathrm{O}_{2}$ concentration was always $<90 \%$ saturation. Slopes of the P-I curves in the light-limited region were determined by linear regression, and were then divided by thallus absorptance to give $\phi$. Slopes for $100 \% I_{0}$ thalli ranged from 0.025 to $0.036 \mathrm{~mol} \mathrm{O}_{2} \mathrm{~mol}^{-1}$ photons, with a mean $r^{2}$ of 0.984 and a mean $95 \%$ confidence interval (CI) of the slope of $0.0088 \mu \mathrm{mol} \mathrm{O}_{2} \mathrm{~mol}^{-1}$ photons, based on 7 to 10 points in each of 30 curves. Most slopes of $9 \% I_{0}$ thalli exposed to $100 \% I_{0}$ were between 0.032 and 0.057 , with a mean $r^{2}$ and $\mathrm{CI}$ of 0.989 and 0.0115 , based on 5 to 10 points in each of 38 curves. Dark respiration $\left(R_{\mathrm{d}}\right)$ was taken as the intercept of this regression. Net photosynthetic capacity $\left(P_{\mathrm{m}}\right)$ was calculated as the average of all values at light saturation. Depression of photosynthetic rate at the highest irradiance $\left(1500 \mu \mathrm{mol}\right.$ photons $\mathrm{m}^{-2} \mathrm{~s}^{-1}$ ) was rarely observed. Other experiments (Levavasseur et al. unpubl.) show that although $U$. rotundata is not $\mathrm{CO}_{2}$ saturated in seawater, quantum yield is not responsive to $\mathrm{CO}_{2}$ or $\mathrm{O}_{2}$ in the range used here, indicating that photorespiration does not complicate interpretation of these data.

Fluorescence measurements. An automated, customized fluorometer was used to measure induction of photosystem II (PSII) chlorophyll fluorescence at $77 \mathrm{~K}$ and $690 \mathrm{~nm}$ (Henley et al. 1991). Sample disks (1 $\mathrm{cm}$ dia.) were lightly dried with tissue paper and appressed directly to the bottom of the quartz rod and secured with a thin metal cap. After 5 min dark adaptation, the rod was immersed a few $\mathrm{cm}$ into liquid $\mathrm{N}_{2}$ for 2 min, then measurement was commenced. Initial fluorescence yield $\left(F_{0}\right)$, which is the basal level when all PSII electron acceptors $\left(Q_{A}\right)$ are oxidized, was determined at the instant the shutter was opened to admit actinic blue light (ca $0.5 \mu \mathrm{mol}$ photons $\mathrm{m}^{-2} \mathrm{~s}^{-1}$ ). Maximum fluorescence yield $\left(F_{\mathrm{m}}\right)$ was determined after complete reduction of all $Q_{\mathrm{A}}$ following several minutes of illumination with blue light. Variable fluorescence $\left(F_{\mathrm{v}}=F_{\mathrm{m}}-\right.$ $F_{\mathrm{o}}$ ), when normalized to $F_{\mathrm{m}}$ is believed to represent PSII photochemical efficiency (Björkman 1987). Data 
acquisition, display and processing, and control of the various filters and shutters were automated using a microcomputer.

A commercial pulse modulation fluorometer (Model PAM-101; Walz, Effeltrich, Germany), as described by Schreiber et al. (1986), was used to determine $F_{\mathrm{o}}, F_{\mathrm{m}}, F_{\mathrm{v}}$, and $F_{\mathrm{v}} / F_{\mathrm{m}}$ at room temperature (RT). At each sampling time, 4 sample disks $(1.1 \mathrm{~cm}$ dia.) were cut and dark adapted for $7 \mathrm{~min}$ in a multiple sample holder. Initial fluorescence was measured using very weak pulsed red light, and $F_{\mathrm{m}}$ was induced by a saturating white light flash (2s) which transiently reduced all $Q_{A}$.

Chlorophyll determination. Chlorophyll (chl) was extracted ( $24 \mathrm{~h}$ dark, room temperature) from the $4 \mathrm{RT}$ fluorescence sample disks in $3 \mathrm{ml}$ of $\mathrm{N}, \mathrm{N}$-dimethylformamide (Henley \& Ramus 1989b). Chl $a$ and $b$ concentrations (area basis) were calculated from absorbance at 664 and $647 \mathrm{~nm}$ (both corrected for scattering by subtracting $700 \mathrm{~nm}$ absorbance), using the equations of Moran (1982).

\section{RESULTS}

\section{Diurnal photosynthetic light response}

Photosynthetic light response (P-I) curves measured at the time of maximum $P_{\mathrm{m}}$ and at dusk are shown for $9 \% I_{0}$ thalli exposed to $100 \% I_{0}$ on 18 May (Fig. 1).

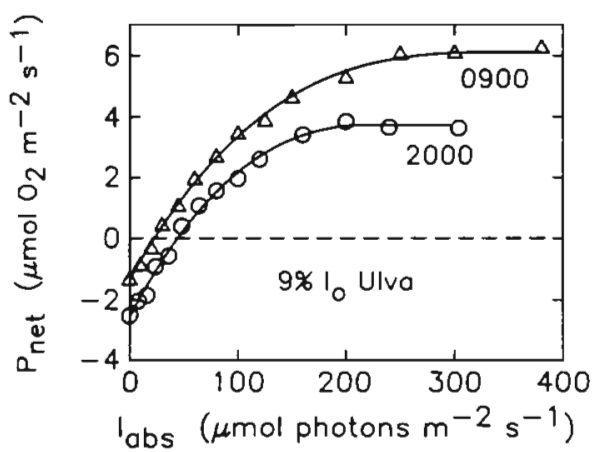

Fig. 1 Ulva rotundata. Photosynthetic light-response curves (absorbed light basis) measured at the indicated times corresponding to dusk and to the diurnal maximum in net $P_{\mathrm{m}}$ for thalli exposed to $100 \% I_{0}$ on 18 May which previously were grown in $9 \% I_{0}$. Rates are normalized to one-sided area

Differences in $P_{\mathrm{m}}$ and $R_{\mathrm{d}}$ are evident, although $\phi$ was similar in these 2 samples. The daily time courses of P-I curve parameters and irradiance traces are summarized in Fig. 2. Net $P_{\mathrm{m}}$ of UIva rotundata thalli grown and measured at $100 \% I_{0}$ exhibited a parabolic diurnal pattern, with a peak value of about $8 \mu \mathrm{mol} \mathrm{O}_{2} \mathrm{~m}^{-2} \mathrm{~s}^{-1}$ at midday and a minimum of about $4 \mu \mathrm{mol} \mathrm{m} \mathrm{m}^{-2} \mathrm{~s}^{-1}$ at dusk (Fig. 2a, open symbols). Quantum yield was highest in early morning, decreased by about $30 \%$ by midday, and showed little change through the afternoon (Fig 2b). Respiration nearly doubled from dawn to dusk (Fig. 2c). Gross $P_{\mathrm{m}}$ (net $P_{\mathrm{m}}+R_{\mathrm{d}}$; dashed curve in
Fig. 2. Ulva rotundata. Diumal patterns of areal (one-sided) $(\mathrm{a}, \mathrm{d})$ net photosynthetic capacity, $(b, e)$ quantum yield and $(c$, f) respiration for thalli exposed to $100 \% I_{0}$ (open symbols) or $9 \% I_{\circ}$ (filled symbols) which were previously grown at (a to $\mathrm{c}$ ) $100 \% I_{0}$ or (d to f) $9 \% I_{0}$. Circles and squares represent consecutive days. Dashed lines in $(a, d)$ are polynomial fits for gross $P_{\mathrm{m}}$ (net $P_{\mathrm{m}}+R_{\mathrm{d}}$ ), and dashed curves in $(b, e)$ indicate $I_{\circ}$ pattern in the tanks on 1 of the 2 experimental dates in each series

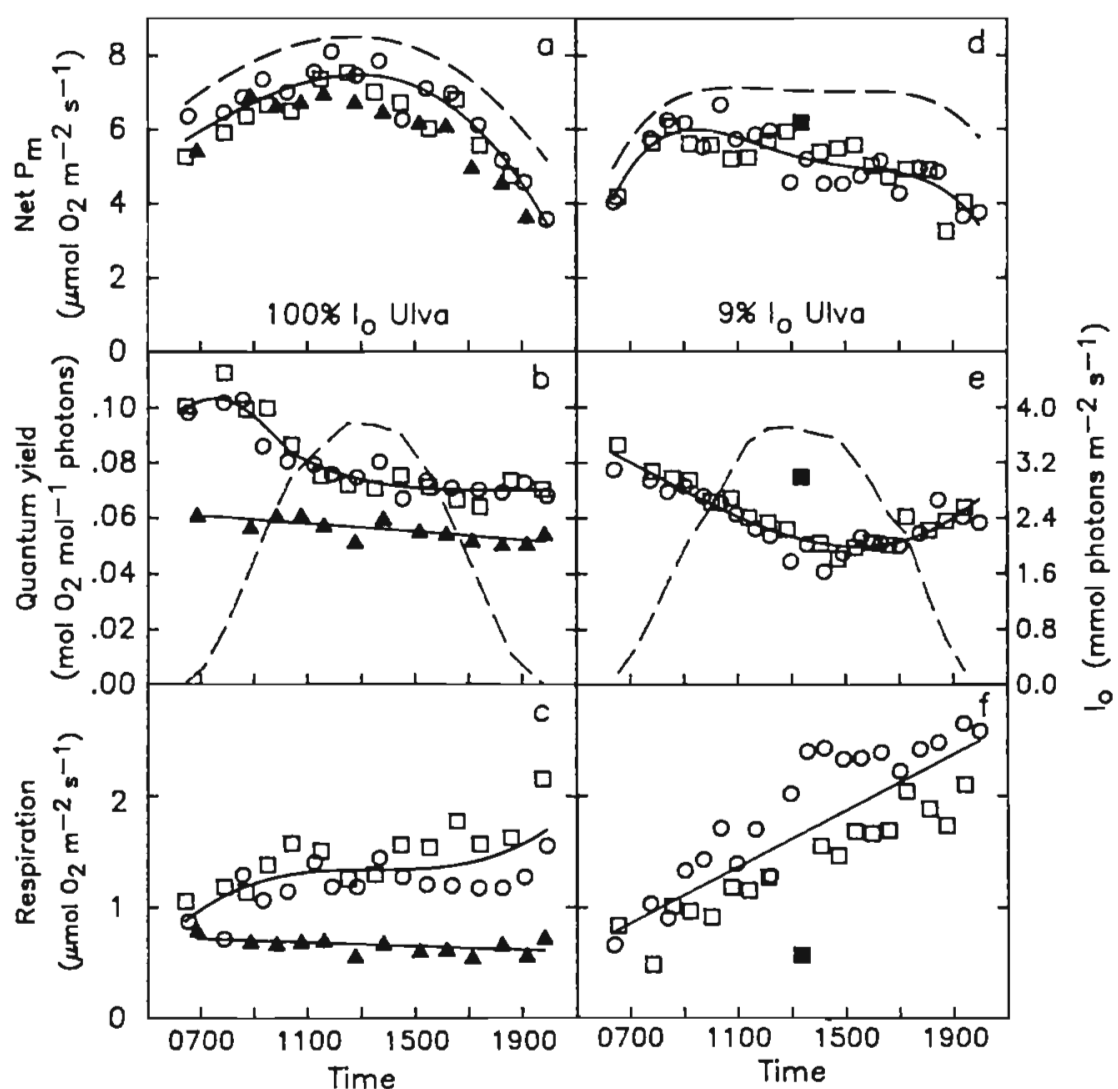


Fig. 2a) followed a more symmetrical daily course than net $P_{\mathrm{m}}$. The pattern of $P_{\mathrm{m}}$ for thalli grown in $100 \% I_{0}$ and then shaded to $9 \% I_{0}$ (Fig. $2 \mathrm{a}$, filled symbols) was similar to that of the same thalli in $100 \% I_{0}$. In contrast, $\phi$ and $R_{\mathrm{d}}$ showed little change through the day when thalli grown in $100 \% I_{0}$ were shaded (Fig. 2b, $c_{\text {, filled }}$ symbols). The systematically lower $\phi$ in this case (determined on 18 September) compared to thalli exposed to $100 \% I_{0}$ (determined on $25 \& 26$ April) is possibly a seasonal difference, although temperature and daylength were similar.

Ulva rotundata thalli grown in $9 \% I_{0}$ and then exposed to $100 \% I_{0}$ for $1 \mathrm{~d}$ showed an early morning induction of net $P_{\mathrm{m}}$ followed by a gradual decline beginning about $3 \mathrm{~h}$ after sunrise and a larger drop at dusk (Fig. 2d). A steady decrease (about $45 \%$ overall) in $\phi$ from dawn to early afternoon was followed by a slight recovery late in the day (Fig. 2e). $R_{\mathrm{d}}$ increased 3 -fold during the day (Fig. 2f), resulting in negligible afternoon decline in gross $P_{\mathrm{m}}$ (dashed curve in Fig. $2 \mathrm{~d}$ ). A $9 \% I_{0}$ control thallus (not exposed to $100 \% I_{0}$ ) exhibited midday values of $P_{\mathrm{m}} \phi$ and $R_{\mathrm{d}}$ comparable to early morning values in thalli transferred to $100 \% I_{0}$ (Fig. 2d, e, f, filled symbols), indicating that the diurnal patterns are due to high irradiance exposure and/or higher integrated irradiation. However, the higher $P_{\mathrm{m}}$ in the $9 \% I_{0}$ control thallus at mid day than at dawn suggests that the early morning induction may be unrelated to high light exposure.

\section{Diurnal fluorescence pattern}

Fluorescence data obtained at $77 \mathrm{~K}$ and RT, and irradiance traces are summarized in Fig. 3. Fluorescence yields of $100 \% I_{0}$ and $9 \% I_{0}$ thalli were very similar at $77 \mathrm{~K}$ (Fig. $3 \mathrm{a}$, e), but at RT were up to twice as high in $9 \% I_{0}$ compared to $100 \% I_{0}$ thalli (Fig. 3c, g).

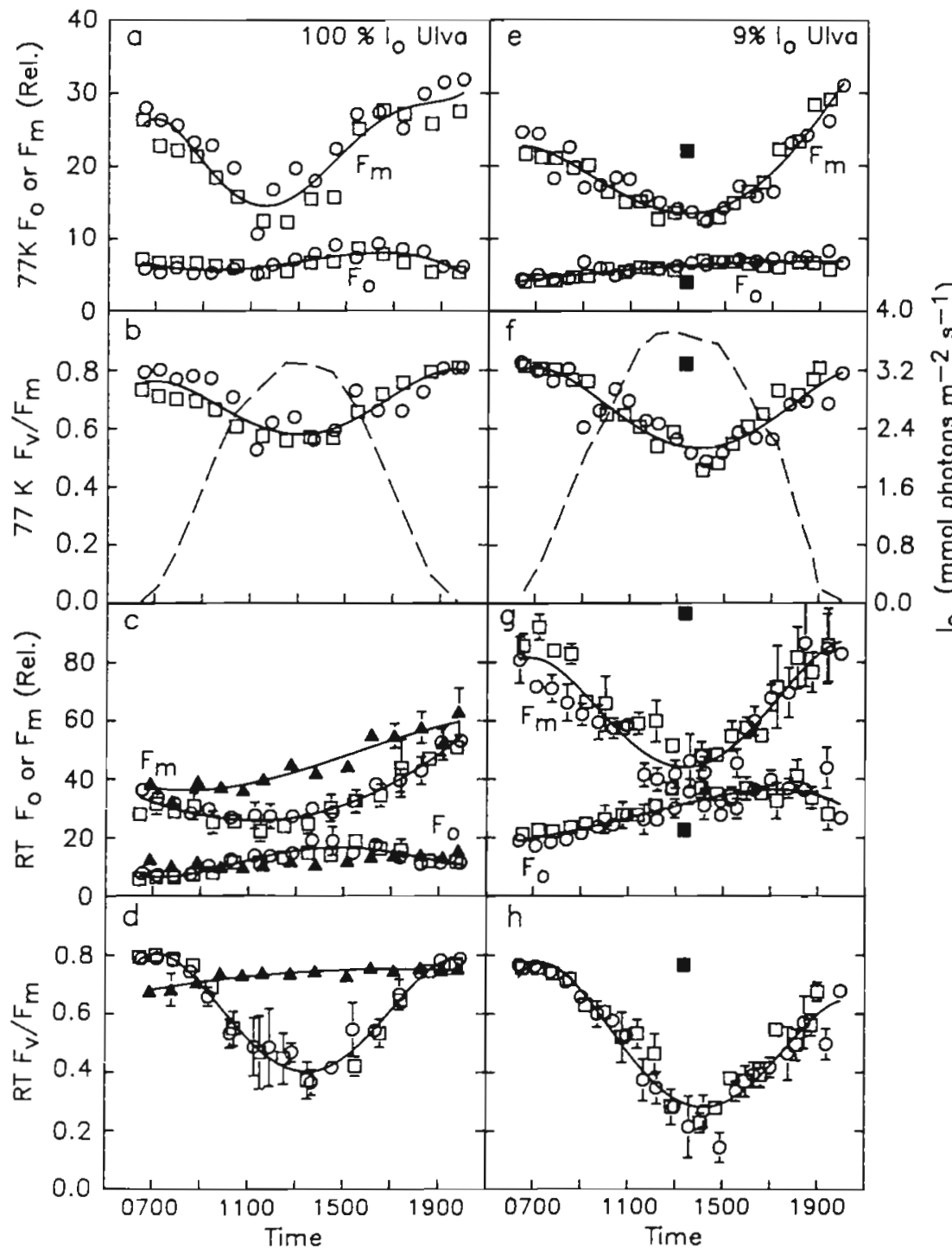

Fig. 3. Ulva rotundata. Diurnal fluorescence parameter patterns measured $(a, b, e, f)$ at $77 \mathrm{~K}$ or $(\mathrm{c}, \mathrm{d}, \mathrm{g}, \mathrm{h})$ at room temperature for thalli exposed to $100 \% I_{0}$ (open symbols) or to $9 \% I_{0}$ (filled symbols) which were previously grown at (a to d) $100 \% I_{0}$ or (e to h) $9 \%$ $I_{0}$. Circles and squares represent consecutive days. Dashed lines $(\mathrm{b}, \mathrm{f})$ indicate $I_{\circ}$ pattern in the tanks on 1 of the 2 experimental dates in each series 
Although the experiments on sun and shade thalli were conducted about 1 mo apart, other data indicate that shade and sun thalli consistently exhibit these relative fluorescence yields. Ulva rotundata thalli grown and measured at $100 \% I_{0}$ exhibited a symmetrical diurnal course of $F_{\mathrm{v}} / F_{\mathrm{m}}$ which inversely tracked instantaneous irradiance. Samples taken at dawn and dusk had values of $F_{\mathrm{v}} / F_{\mathrm{m}}$ close to 0.8 measured at either $77 \mathrm{~K}$ (Fig. 3b) or RT (Fig. 3d), but midday values were lower at RT $(0.4$ versus 0.6$)$. Both $F_{\mathrm{m}}$ and $F_{0}$ followed more complex patterns. There was a 2 -fold drop in $77 \mathrm{~K} F_{\mathrm{m}}$ over the first $5 \mathrm{~h}$ of daylight, then a recovery to dawn levels, or perhaps slightly higher, by dusk (Fig. 3a). $F_{\circ}$ at $77 \mathrm{~K}$ followed a similar qualitative pattern to that of $F_{\mathrm{m}}$, except for a decrease over the last $3 \mathrm{~h}$ of daylight (Fig. 3a). At RT, $F_{\mathrm{m}}$ declined by about $20 \%$ over the first $5 \mathrm{~h}$, then increased through the afternoon to a value at dusk which was about $50 \%$ higher than at dawn (Fig. 3c). Room temperature $F_{0}$ behaved in a manner similar to $77 \mathrm{~K} F_{0}$, except that it started to rise earlier in the day (Fig. 3c).

In Ulva rotundata thalli grown at $100 \% I_{0}$ and shaded to $9 \% I_{0}, \mathrm{RT} F_{\mathrm{v}} / F_{\mathrm{m}}$ did not exhibit a midday decline, and actually increased slightly through the day (Fig. 3d, filled symbols). $F_{\circ}$ and $F_{\mathrm{m}}$ in these thalli showed little change in the morning, but increased by about $30 \%$ and $50 \%$, respectively, during the afternoon (Fig. 3c, filled symbols). $F_{\mathrm{v}} / F_{\mathrm{m}}$ was systematically less than the 0.8 value observed in uninhibited thalli in April, in agreement with the lower $\phi$ noted above.

Diurnal patterns of RT and $77 \mathrm{~K} F_{\mathrm{v}} / F_{\mathrm{m}}$ for Ulva rotundata thalli grown at $9 \% I_{0}$ and exposed for $1 \mathrm{~d}$ to $100 \%$ $I_{0}$ are similar to those of thalli grown at $100 \% I_{0}$, except that the minima were lower $(0.5$ at $77 \mathrm{~K}$ and 0.25 at RT) and occurred about $1 \mathrm{~h}$ after solar noon, and recovery was not quite complete by dusk (Fig. 3f, h). $F_{\mathrm{m}}$ at $77 \mathrm{~K}$ declined through midday, and rapidly recovered starting $2 \mathrm{~h}$ after midday to a dusk value about $30 \%$ higher than at dawn (Fig. $3 e$ ). At RT, in contrast, the diurnal $F_{m}$ pattern was symmetrical with a midday minimum (Fig. $3 g)$. Unlike $100 \% I_{0}$ thalli, $9 \% I_{0}$ thalli exhibited a steadily increasing $F_{0}$ throughout the day at both $77 \mathrm{~K}$ and RT (Fig. 3e, g). As with P-I curve parameters, the $9 \% I_{0}$ control thalli have equal fluorescence values when measured in early morning or midday (Fig. 3e to $h$, filled symbols), indicating that the diurnal patterns are induced by high irradiance and/or higher integrated irradiation. An earlier experiment (not shown) indicated that $77 \mathrm{~K} F_{\mathrm{v}} / F_{\mathrm{m}}$ stayed near 0.8 all day in $9 \%$ $I_{\circ}$ control thalli.

Plots of $77 \mathrm{~K} F_{\mathrm{v}} / F_{\mathrm{m}}$ as a function of in situ irradiance (not shown) show no hysteresis between morning and afternoon in Ulva rotundata thalli grown and measured at $100 \% I_{0}$, and a slight offset in thalli grown at $9 \% I_{\circ}$ and exposed to $100 \% I_{0}$. At RT, $F_{v} / F_{\mathrm{m}}$ exhibited a slight afternoon hysteresis in $100 \% I_{0}$ thalli and a large offset (about 0.2 ) in $9 \% I_{0}$ thalli exposed to $100 \% I_{0}$ at a given irradiance.

\section{Relationship between quantum yield and fluorescence}

Comparison of the diurnal courses of $\phi$ (Fig. 2b, e) and $F_{\mathrm{v}} / F_{\mathrm{m}}$ (Fig. 3b, d, f, h) suggests that $F_{\mathrm{v}} / F_{\mathrm{m}}$ and $\phi$ are not strongly related throughout the day. In fact, a significant linear correlation is evident before midday whether $F_{\mathrm{v}} / F_{\mathrm{m}}$ is determined at $77 \mathrm{~K}$ or RT (Fig. 4) in both $9 \% I_{0}$ thalli $(77 \mathrm{~K}: \mathrm{r}=0.817, \mathrm{p}<0.01$; RT: $\mathrm{r}=$ $0.929, p<0.01)$ and $100 \% I_{0}$ thalli $(77 \mathrm{~K}: r=0.738$, $\mathrm{p}<0.01$; RT: $\mathrm{r}=0.963, \mathrm{p}<0.01$ ). However, there is no relationship between these parameters after midday in $100 \% I_{0}$ thalli (Fig. 4a, b; $77 \mathrm{~K}: \mathrm{r}=0.344, \mathrm{p}>0.05 ; \mathrm{RT}$ : $r=0.215, p>0.05)$. The relationship is still significant in $9 \% I_{0}$ thalli during the afternoon (Fig. $4 \mathrm{c}, \mathrm{d} ; 77 \mathrm{~K}: \mathrm{r}=$ $0.798, p<0.01 ; R T: r=0.783, p<0.01$ ), although the 'slope' of the relationship and the $r$ values are smaller than in the morning. Thus, $F_{\mathrm{v}} / F_{\mathrm{m}}$ can be a poor indicator of photosynthetic efficiency in the afternoon under some growth conditions.

\section{Chlorophyll content and absorptance}

Ulva rotundata thalli grown at $9 \% I_{0}$ and exposed to $100 \% I_{0}$ had a stable absorptance and chl content on an area basis throughout the day (Fig. 5). In contrast,

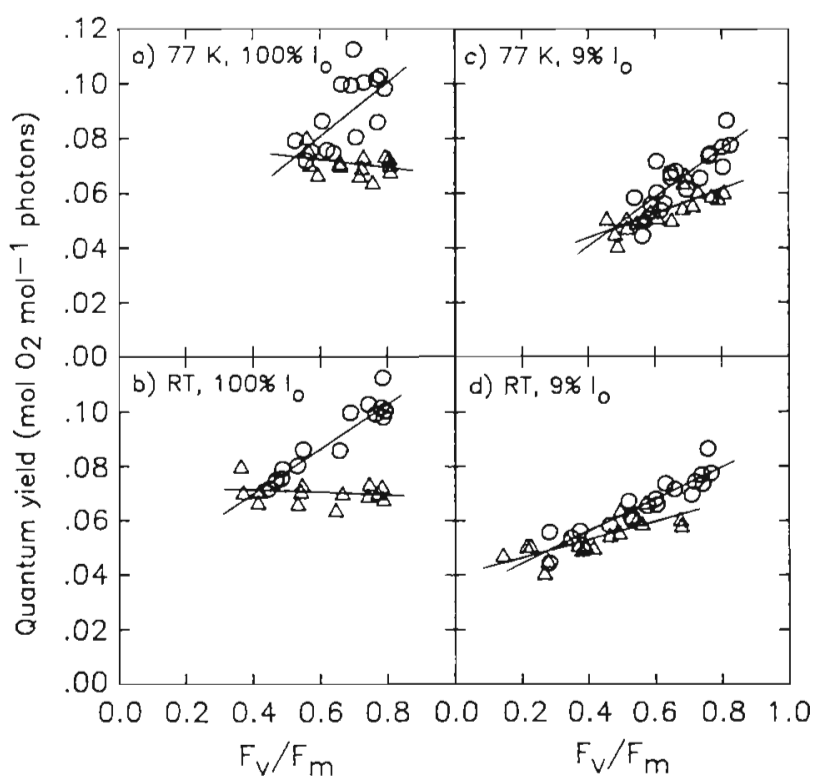

Fig. 4. Ulva rotundata. Relationship between $F_{\mathrm{v}} / F_{\mathrm{m}}$ measured $(\mathrm{a}, \mathrm{c})$ at $77 \mathrm{~K}$ or $(\mathrm{b}, \mathrm{d})$ at room temperature and quantum yield for thalli exposed to $100 \% I_{0}$ which were previously grown at $(\mathrm{a}, \mathrm{b}) 100 \% I_{0}$ or $(\mathrm{c}, \mathrm{d}) 9 \% I_{0}$. Circles are a.m. values, and triangles are p.m. values ( $2 \mathrm{~d}$ pooled). See text for correlation coefficients 


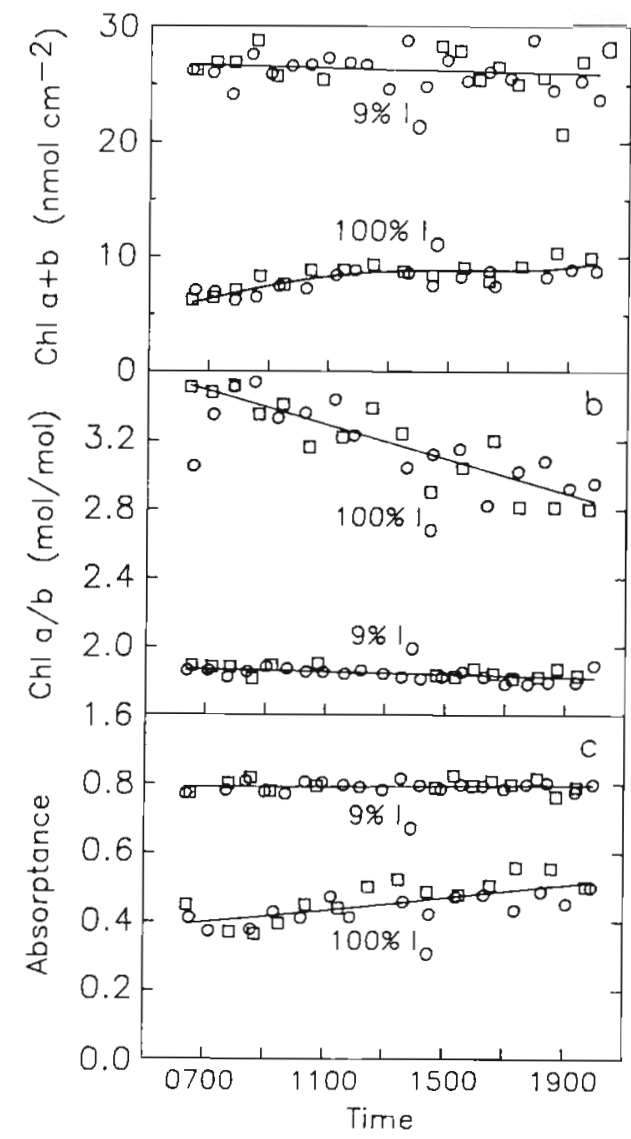

Fig. 5. Ulva rotundata. Diumal patterns of (a) chl $(a+b)$ content, (b) chl $a / b$ ratio and (c) thallus absorptance for thalli exposed to $100 \% I_{0}$ which were previously grown at $100 \% I_{0}$ or $9 \% I_{0}$

$100 \% I_{\circ}$ thalli exhibited an upward trend in absorptance and areal chl $(a+b)$ content (Fig. 5a, c) and a downward trend in chl $a / b$ ratio (Fig. $5 b$ ). For $100 \% I_{\circ}$ thalli, chl $(a+b)$ data are correlated with absorptance $(r=0.703, p<0.01)$.

\section{DISCUSSION}

\section{Diurnal photosynthetic performance}

Ulva rotundata thalli grown at $100 \% I_{0}$ had virtually identical photosynthetic capacity at a given in situ $I_{0}$ in morning and afternoon (Fig. 2a), and only a slight hysteresis occurred in $9 \% I_{0}$ thalli exposed to $100 \% I_{\circ}$ (Fig. 2d). We interpret this as absence of a substantial midday or afternoon depression. Much of the small hysteresis in $9 \% I_{0}$ thalli was apparently caused by the large diurnal increase in $R_{\mathrm{d}}$ (Fig. $2 \mathrm{~d}, \mathrm{f}$ ). Our results therefore differ from those of previous studies with macrophytes, in which photosynthetic performance exhibited an obvious morning peak or a bimodal pat- tern (Meyer 1939, McCracken et al. 1975, Titlyanov et al. 1978, Ramus \& Rosenberg 1980, Coutinho \& Zingmark 1987, Huppertz et al. 1990). In most of those studies, only net photosynthetic performance was measured, and P-I parameters $\left(P_{\mathrm{m}}, \phi, R_{\mathrm{d}}\right)$ were not determined. It is possible that either a temporary or sustained diurnal increase in $R_{d}$ could explain those earlier results, as suggested for phytoplankton (Falkowski et al. 1985, Schanz \& Dubinsky 1988). Also, the $100 \% I_{0}$ thalli in our experiments are much more sun-acclimated [low chl $(a+b)$ and high $c h l a / b$ ratio] and are probably more tolerant of midday irradiance than typical field specimens. In a diurnal series of incubations of $100 \% I_{0}$ thalli in bottles (20 to $30 \mathrm{~min}$ ) in full sunlight in October 1986, there also was no evidence of midday depression, indicating that determination of photosynthetic capacity in red light does not explain our results. Moreover, the $P_{\mathrm{m}}$ values obtained by the 2 methods were very similar.

Diurnal photosynthetic performance of Ulva rotundata in our outdoor tumble tanks was largely determined by the pattern of $P_{m}$, as photosynthesis was light-saturated for all except approximately the first and last $45 \mathrm{~min}$ of the day. Diurnal changes in $\phi$ (Fig. $2 \mathrm{~b}$, e) were therefore of little consequence to integrated diurnal production. Photosynthetic capacity in thalli grown at $100 \% I_{0}$ varied as much as 2 -fold through the day (Fig. 2a), and the pattern was virtually identical qualitatively to that obtained in a study of European Ulva sp. using traditional bottle incubations in white light (Levavasseur \& Giraud 1982). This amplitude is less than or equal to the diel ranges reported previously for Ulva lactuca (Mishkind et al. 1979), natural assemblages and laboratory cultures of phytoplankton (e.g. Erga \& Skjoldal 1990). Whereas most phytoplankton studies in which both $P_{\mathrm{m}}$ and $\phi$ were determined exhibited a positive correlation in these parameters, $P_{\mathrm{m}}$ varied independently of $\phi$ in $U$. rotundata (Fig. $2 \mathrm{a}, \mathrm{b}, \mathrm{d}$, e), U. lactuca (Mishkind et al. 1979), Euglena gracilis (Waither \& Edmunds 1973), and some natural phytoplankton assemblages (MacCaull \& Platt 1977, Putt \& Prézelin 1985).

The photosynthetic periodicity observed in UIva rotundata thalli grown at $100 \% I_{0}$ is clearly unrelated to chlorophyll changes, based on their different time courses (cf. Figs. 2a, 5a). Diel ambient nutrient fluctuations, which sometimes have been implicated in diel photosynthesis changes (Stross et al. 1973, Erga \& Skjoldal 1990), were eliminated in our experiments by continuous enrichment with $\mathrm{N}$ and $\mathrm{P}$. We also have data which suggest that $N$ uptake rate by $U$. rotundata does not vary markedly through the day; even if it did, control would be endogenous, possibly related to cell cycle entrainment. Photoinhibition is an unlikely explanation for the afternoon dropoff in $P_{\mathrm{m}}$ in $100 \% I_{\mathrm{o}}$ thalli, 
because the rate of decline accelerated as $I_{0}$ decreased, and the decline occurred even when thalli were shaded for the entire day (Fig. 2a). Feedback regulation by accumulated photosynthetic end products late in the day (Meyer 1939, Levavasseur \& Giraud 1982, Falkowski et al. 1985, Schanz \& Dubinsky 1988) also appears not to be the cause, because thalli grown at $100 \% I_{0}$ and then shaded to subsaturating irradiance $\left(9 \% I_{\mathrm{o}}\right)$ also exhibited a large diurnal change in $P_{\mathrm{m}}$ and no increase in $R_{d}$ (Fig. $2 \mathrm{a}, \mathrm{c}$, filled symbols). One remaining explanation of the diurnal pattern in $P_{\mathrm{m}}$ involves up- (a.m.) and down-regulation (p.m.), either of an electron transfer component (Senger \& Bishop 1967, Senger 1970b, Prézelin \& Sweeney 1977, Mishkind et al. 1979) or carbon metabolism (Walther \& Edmunds 1973).

The diel $P_{\mathrm{m}}$ fluctuation was found to be free-running in constant low level illumination in Ulva lactuca (Mishkind et al. 1979) and Porphyra yezoensis (Oohusa 1980). Free-running endogenous rhythms in photosynthesis are common in microalgae (Palmer et al. 1964, Prézelin \& Sweeney 1977, Prézelin et al. 1977, Prézelin \& Matlick 1980, Harding et al. 1981). Thus, it is conceivable that the morning 'induction' and afternoon decline in $P_{\mathrm{m}}$ are the reverse of the same endogenous regulatory process. This phenomenon may or may not be related to cell cycle synchrony (Senger 1970a, b, Prézelin \& Sweeney 1977). It is also possible that such a rhythm could explain previous reports of afternoon depression of photosynthesis in macroalgae, if the intrinsic peak occurred during the morning. This pattern could then be further modified by the $R_{\mathrm{d}}$ changes discussed above.

\section{Diurnal pattern of $\phi$ and fluorescence}

The diurnal pattern of $\phi$ (Fig. 2b, e) is clearly different than that of $P_{\mathrm{m}}$ (Fig. $2 \mathrm{a}, \mathrm{d}$ ): the maximum $\phi$ occurred at or shortly after dawn and a minimum was reached by about midday. In Ulva rotundata thalli grown at $100 \% I_{0}$, no change in $\phi$ occurred after solar noon despite very high $I_{\circ}$ (Fig. 2b). This suggests that the morning decline was due either directly to induction of a photoprotective mechanism, or to photodamage followed by onset of photoprotection to prevent further loss of photosynthetic efficiency. The latter seems less likely because photoprotection by thermal deexcitation is itself associated with a decline in $\phi$ (Demmig-Adams 1990). In the absence of photoprotection, photodamage would be expected to occur fastest when $I_{0}$ was highest, which was not the case. Even in thalli grown at $9 \% I_{0}$ and exposed to $100 \% I_{0}$, the rate of decline in $\phi$ was constant through midday and then $\phi$ leveled off about 1 to $2 \mathrm{~h}$ after solar noon, while $I_{\mathrm{o}}$ was still very high.

The fluorescence data (Fig. 3) are consistent with the conclusion that photoprotection rather than photodamage was the primary cause of the diurnal pattern of $\phi$ in Ulva rotundata thalli grown at $100 \% I_{0}$. The afternoon recovery of $F_{\mathrm{v}} / F_{\mathrm{m}}$ started while $I_{0}$ was still far above a level saturating for photosynthesis (Fig. $3 b$, d), and $F_{m}$ started to recover prior to solar noon (Fig. 3a, c). The behavior of $F_{0}$ was more complex (Fig. $3 \mathrm{a}, \mathrm{c}$ ). On a theoretical basis, a decrease at $77 \mathrm{~K}$ in both $F_{\mathrm{o}}$ and $F_{\mathrm{m}}$ is believed to reflect primarily photoprotection via thermal deexcitation, whereas an increase in $F_{o}$ and decrease in $F_{\mathrm{m}}$ is ascribed to photosystem II damage (Björkman 1987). If this is true, the slight morning decline in $77 \mathrm{~K}$ fluorescence (Fig. 3a) indicates photoprotection. The afternoon rise in $F_{0}$ may indicate concurrent photodamage and photoprotection, where the tendency for $F_{0}$ to increase due to damage exceeds the decrease due to protection. Indeed, in various species acclimated to shade and exposed for 2 to $3 \mathrm{~h}$ to high light, some showed an average increase in $F_{0}$ of about $50 \%$, whereas others responded with a 10 to $20 \%$ drop in $F_{0}$ (Björkman 1987). The late afternoon decline in $77 \mathrm{~K} F_{0}$ (Fig. $3 a$ ) could then be attributed to repair of damaged PSII centers. Preliminary evidence (Henley et al. 1991) confirmed that $U$. rotundata has an inducible violaxanthin-zeaxanthin cycle, which in higher plants is associated with thermal deexcitation (DemmigAdams 1990).

Using this same analysis, Ulva rotundata thalli grown at $9 \% I_{\circ}$ and exposed to $100 \% I_{0}$ show a $77 \mathrm{~K} F_{\circ}$ increase indicative of photodamage (Fig. 3e). Photoprotection also may occur simultaneously in this case, as suggested by the diurnal pattern of $\phi$ relative to $I_{0}$ (Fig. $2 e$ ) and the fact that the decline in $P_{\mathrm{m}}$ can be explained by an increase in $R_{\mathrm{d}}$ (Fig. $2 \mathrm{~d}, \mathrm{f}$ ).

A theoretical model of organization of the light reactions of photosynthesis (Butler \& Kitajima 1975) predicted that $\phi$ and $F_{\mathrm{v}} / F_{\mathrm{m}}$ should be directly related. This has been confirmed by numerous laboratory experiments with higher plants (e.g. Demmig \& Björkman 1987) and in Ulva rotundata following transfer to bright light in indoor culture (Henley et al. 1991). However, no detailed diurnal studies of these parameters under natural conditions have been published. The relationship seems valid during the morning, but not the afternoon, in $U$. rotundata thalli grown at $100 \% I_{0}$ (Fig. $4 \mathrm{a}$, b). This observation is unlikely to be an artifact of different recovery times for P-I and fluorescence samples; prior to measurement, the former remain in darkness or low irradiance at least as long as the fluorescence samples, and therefore would allow $\phi$ to recover more than $F_{\mathrm{v}} / F_{\mathrm{m}}$. Moreover, such an effect should not vary with time of day. Our data are clearly an exception 
to the Butler model, although the cause is not yet known. It is conceivable that $\phi$ is down-regulated along with $P_{\mathrm{m}}$ in the late afternoon, via a mechanism that does not prevent recovery of variable fluorescence. Interpretation of the lack of correspondence between $\phi$ and $F_{\mathrm{v}} / F_{\mathrm{m}}$ may be facilitated by our ongoing mechanistic studies of photoinhibition in this species.

Fluorescence theory in relation to photosynthesis was developed using low temperature $(77 \mathrm{~K})$ to completely block reoxidation of the PSII electron acceptor, $Q_{A}$. While this method is still useful, recent perfection of lock-in amplification technology allows much more versatile fluorescence analysis under ambient light and temperature conditions (Schreiber et al. 1986). Current research on higher plants and our ongoing studies on macroalgae require the additional information accessible using pulse modulation fluorescence. Here and in a previous report (Henley et al. 1991), we have performed both types of fluorescence measurements in parallel to determine the extent to which they agree under various conditions. Our results indicate qualitative agreement between the 2 techniques, but a greater dynamic range at room temperature.

\section{Chlorophyll content and absorptance}

Endogenously controlled chloroplast movements and corresponding changes in absorptance have been reported for some seaweeds, including Ulva lactuca and $U$. fenestrata, but are unrelated to diel photosynthetic patterns (Britz \& Briggs 1976, Titlyanov et al. 1978, Nultsch et al. 1981). We found no diurnal change in absorptance in $U$. rotundata thalli grown at $9 \% I_{0}$ and exposed for $1 \mathrm{~d}$ to $100 \% I_{0}$, and a small but steady increase through the day in $100 \% I_{0}$ thalli (Fig. 5c). The latter does not resemble the pattern found in $U$. fenestrata (Titlyanov et al. 1978), but in both cases the absorptance changes are correlated with chl content rather than chloroplast movement. Although our estimates of absorptance did not take into account reflectance, this component was only about $6 \pm 2 \%$ in spectral scans of U. lactuca, and was lowest at strongly absorbed wavelengths such as those used in our photosynthesis measurements (Lüning \& Dring 1985). There is no reason to believe that reflectance changed markedly through the day. Thus, any underestimate of $\phi$ caused by ignoring reflectance is small and does not alter the diurnal trends.

Titlyanov et al. (1978) observed an increase in chl content in Ulva fenestrata of about $20 \%$ during early morning, followed by a stable level through sunset. Similarly, chl $(a+b)$ content of $100 \% I_{0}$ thalli of $U$. rotundata increased about $40 \%$ through the day, primarily during the morning and late afternoon (Fig. 5a).
A concurrent decline in the chl $a / b$ ratio (Fig. 5b) suggests a differential synthesis of the various pigment protein complexes through the day. The physiological significance of these patterns is unknown, although it may be related to cell cycle phenomena. Exposure of $9 \% I_{0}$ thalli of $U$. rotundata to $100 \% I_{0}$ did not result in any trend in either chl $(a+b)$ or chl $a / b$, which at first appears to contradict earlier observations of a large decrease in chl $(a+b)$ following a 9 to $100 \% I_{0}$ transfer in this species (Henley \& Ramus 1989c). However, the previous chl $(a+b)$ data were normalized to dry weight, whereas here we reported values on an area basis. The discrepancy can be explained by a change in the dry/fresh weight and dry weight/area ratios which invariably occur in $U$. rotundata under these conditions (Henley \& Ramus 1989c, Henley 1990).

\section{Effect of sun/shade acclimation on diurnal response}

We have presented detailed diurnal photosynthesis and fluorescence data for Ulva rotundata thalli from 3 light regimes: sun-acclimated and shade-acclimated thalli measured during exposure to full sunlight, and sun thalli shaded for $1 \mathrm{~d}$, which helped to determine which features of the response depend on high light exposure. Single midday values were also obtained for shaded control thalli. The overall trends in photosynthesis and fluorescence parameters were similar in sun and shade thalli exposed to full sunlight, but differences in detail suggest qualitatively different responses in the 2 groups of thalli. Maximum $P_{\mathrm{m}}$ was about $25 \%$ higher, probably reflecting a greater content of ribulose-1,5-bisphosphate carboxylase, and exhibited greater diurnal variation in sun thalli. In contrast, shade thalli possessed greater light harvesting capacity, resulting in higher initial slopes of the P-I response, when uncorrected for absorptance. This increased light harvesting potential in shade $U$. rotundata reflects an increase in both numbers of reaction centers and antenna size, particularly photosystem II (Levavasseur 1989). The combination of greater energy capture per PSII and reduced carboxylation capacity renders shade thalli more sensitive to high light. Consequently, shade thalli exposed to full sunlight showed a greater decline in $\phi$ and $F_{\mathrm{v}} / F_{\mathrm{m}}$ and a larger increase in $R_{\mathrm{d}}$ compared to sun thalli. Changes in $F_{o}$ indicated a smaller propensity for photoprotection, and a greater tendency for photodamage in shade thalli.

Our results indicate that $P_{\mathrm{m}}, \phi$, and $R_{\mathrm{d}}$ all vary with time of day, so that P-I curves determined at one time of the day cannot necessarily be accurately extrapolated to determine diurnal production (Ramus \& Rosenberg 1980). The validity of that approach will depend on species, previous as well as current irradiance, and 
possibly also factors such as temperature and nutrition. Diurnal variability of the P-I relationship also complicates estimation of the periods above compensation ( $H_{\text {comp }}$ ) and saturation $\left(H_{\text {sat }}\right)$. These have been used to explain bathymetric distribution of seagrasses and to estimate their diurnal production from P-I curves which were not determined in real time (Dennison \& Alberte $1985,1986)$. The present results begin to ascribe physiological mechanisms to statistically modeled photosynthetic response functions (Neale \& Marra 1985). Ongoing studies of Ulva rotundata on an intertidal sand flat should improve our understanding of its photosynthetic response to interacting environmental factors.

Acknowledgements. This research was supported by National Science Foundation (NSF) grant OCE-8812157 to C.B.O. and J.R., and by a Centre National de la Recherche Scientifique/ NSF exchange fellowship to G.L. The manuscript was greatly improved by the comments of $\mathrm{M}$. J. Dring and an anonymous reviewer.

\section{LITERATURE CITED}

Björkman, O. (1987). Low-temperature chlorophyll fluorescence in leaves and its relationship to photon yield of photosynthesis in photoinhibition. In: Kyle, D. J., Osmond, C. B., Arntzen, C. J. (eds.) Topics in photosynthesis, Vol. 9, Photoinhibition. Elsevier, Amsterdam, p. 123-144

Blinks, L. R., Givan, C. V. (1961). The absence of daily photosynthetic rhythm in some littoral marine algae. Biol. Bull. mar biol. Lab., Woods Hole 121. 230-233

Britz, S. J., Briggs, W. R. (1976). Circadian rhythms of chloroplast orientation and photosynthetic capacity in Ulva. Plant Physiol. 58: 22--27

Butler, W. L., Kitajima, M. (1975). Fluorescence quenching in photosystem II of chloroplasts. Biochim. Biophys. Acta 376: $116-125$

Chow, W. S., Osmond, C. B., Huang, L. K. (1989). Photosystem II function and herbicide binding sites during photoinhibition of spinach chloroplasts in-vivo and in-vitro. Photosynth. Res. 21: 17-26

Coutinho, R., Zingmark, R. (1987). Diurnal photosynthetic responses to light by macroalgae. J. Phycol. 23: 336-343

Critchley, C. (1988). The molecular mechanism of photoinhibition - facts and fiction. Aust. J. Plant Physiol. 15: 195-205

Demmig-Adams, B. (1990). Carotenoids and photoprotection in plants: a role for the xanthophyll zeaxanthin. Biochim. Biophys. Acta 1020: 1-24

Demmig, B., Björkman, O. (1987). Comparison of the effects of excessive light on chlorophyll fluorescence $(77 \mathrm{~K})$ and photon yield of $\mathrm{O}_{2}$ evolution in leaves of higher plants. Planta 171: 171-184

Dennison, W C., Alberte, R. S. (1985). Role of daily light period in the depth distribution of Zostera marina (eelgrass). Mar. Ecol. Prog. Ser. 25: 51-61

Dennison, W. C., Alberte, R. S. (1986). Photoadaptation and growth of Zostera marina L. (eelgrass) transplants along a depth gradient. J. exp. mar. Biol. Ecol. 98: 265-282

Erga, S. R., Skjoldal, H. R. (1990). Diel variations in photosynthetic activity of summer phytoplankton in Lindåspollene, western Norway. Mar Ecol. Prog. Ser. 65: 73-85

Falkowski, P. G., Dubinsky, Z., Santostefano, G. (1985). Light- enhanced dark respiration in phytoplankton. Verh. int. Verein. Limnol. 22: 2830-2833

Harding, L. W. Jr, Meeson, B. W., Prézelin, B. B., Sweeney, B M. (1981). Diel periodicity of photosynthesis in marine phytoplankton. Mar Biol. 61. 95-105

Harris, G. P., Piccinin, B. B. (1977). Photosynthesis by natural phytoplankton populations. Arch. Hydrobiol. 80: 405-457

Henley, W. J. (1990). Uncoupling of various measures of growth in Ulva rotundata (Chlorophyta) following a large decrease in irradiance. J. Phycol, 26: 206-207

Henley, W. J., Levavasseur, G., Franklin, L. A. Osmond, C. B., Ramus, J. (1991). Photoacclimation and photoinhibition in Ulva rotundata as influenced by nitrogen availability. Planta 184: 235-243

Henley, W J., Ramus, J. (1989a). Photoacclimation of Ulva rotundata under steady state conditions. Mar. Biol. 103: 261-266

Henley, W. J., Ramus, J. (1989b). Optimization of pigment content and the limits of photoacclimation for Ulva rotundata. Mar. Biol. 103: 267-274

Henley, W. J., Ramus, J. (1989c). Time course of physiological response of Ulva rotundata to growth irradiance transitions. Mar. Ecol. Prog. Ser. 54: 171-177

Huppertz, K., Hanelt, D., Nultsch, W. (1990). Photoinhibition of photosynthesis in the marine brown alga Fucus serratus as studied in field experiments. Mar Ecol. Prog. Ser. 66: $175-182$

Krause, G. H. (1988). Photoinhibition of photosynthesis. An evaluation of damaging and protective mechanisms Physiol. Plant. 74: 566-574

Levavasseur, G. (1989). Analyse comparé des complexes pigment-protéines de chlorophycophytes marines benthique. Phycologia 28: 1-14

Levavasseur, G., Giraud, G. (1982). Modification de la photosynthèse nette d'une Ulve de Roscoff en fonction de la durée d'éclairement. Physiol. Vég. 20: 143-154

Lüning, K., Dring, M. J. (1985). Action spectra and spectral quantum yield of photosynthesis in marine macroalgae with thin and thick thalli. Mar Biol. 87: 119-129

MacCaull, W. A., Platt. T (1977). Diel variations in the photosynthetic parameters of coastal marine phytoplankton Limnol. Oceanogr. 22: 723-731

McCracken, M. D., Adams, M. S., Titus, J., Stone, W (1975). Diumal course of photosynthesis in Myriophyllum spicatum and Oedogonium. Oikos 26: 355-361

Meyer, B. S. (1939). The daily cycle of apparent photosynthesis in a submerged aquatic. Am. J. Bot. 26: 755-760

Mishkind, M., Mauzerall, D., Beale, S. I. (1979). Diurnal variation in situ of photosynthetic capacity in Ulva is caused by a dark reaction. Plant Physiol. 64: 896-899

Moran, R. (1982). Formulae for determination of chlorophyllous pigments extracted with $\mathrm{N}, \mathrm{N}$-dimethylformamide Plant Physiol. 69: 1376-1381

Neale, P. J. (1987). Algae photoinhibition and photosynthesis in the aquatic environment. In: Kyle, D. J., Osmond, C. B., Arntzen, C. J. (eds.) Topics in photosynthesis, Vol. 9, Photoinhibition. Elsevier, Amsterdam, p. 39-65

Neale, P. J., Marra, J. (1985). Short-term variation of $P_{\max }$ under natural irradiance conditions: a model and its implications. Mar Ecol. Prog. Ser. 26: 113-124

Nultsch, W., Pfau, J., Rüffer, U. (1981). Do correlations exist between chromatophore arrangement and photosynthetic activity in seaweeds? Mar. Biol. 62: 111-117

Okada, M., Inoue, M., Ikeda, T (1978). Circadian rhythm of photosynthesis in Bryopsis maxima. Plant Cell Physiol. 19: $197-202$

Oohusa, T (1980). Diurnal rhythm in the rates of cell division, 
growth and photosynthesis of Porphyra yezoensis (Rhodophyceae) cultured in the laboratory. Botanica mar. 23: $1-5$

Palmer, J. D., Livingston, L., Zusy, F. D. (1964). A persistent diurnal rhythm in photosynthetic capacity. Nature, Lond. 203: 1087-1088

Prézelin, B. B., Matlick, H. A. (1980). Time-course of photoadaptation in the photosynthesis-irradiance relationship of a dinoflagellate exhibiting photosynthetic periodicity. Mar. Biol. 58: 85-96

Prézelin, B. B., Meeson, B. W., Sweeney, B. M. (1977). Characterization of photosynthetic rhythms in marine dinoflagellates. I. Pigmentation, photosynthetic capacity and respiration. Plant Physiol. 60: 384-387

Prézelin, B. B., Sweeney, B. M. (1977). Characterization of photosynthetic rhythms in marine dinoflagellates. II. Photosynthesis-irradiance curves and in vivo chlorophyll a fluorescence. Plant Physiol. 60: 388-392

Putt, M. Prézelin, B. B. (1985). Observations of diel patterns of photosynthesis in cyanobacteria and nanoplankton during 'el Niño'. J. Plankton Res. 7: 779-790

Ramus, J., Rosenberg, G. (1980). Diurnal photosynthetic performance of seaweeds measured under natural conditions Mar. Biol. 56: 21-28

Schanz, F., Dubinsky, Z. (1988). The afternoon depression in primary productivity in a high rate oxidation pond. $J$. Plankton Res. 10: 373-383

This article was presented by $M$. J. Dring, Belfast, UK
Schreiber, U., Schliwa, U., Bilger, W (1986). Continuous recording of photochemical and nonphotochemical chlorophyll fluorescence quenching with a new type of modulation fluorometer. Photosynthesis Res. 10: 51-62

Senger, H. (1970a). Charakterisierung einer Synchronkultur von Scenedesmus obliquus, ihrer potentiellen Photosyntheseleistung und des Photosynthese-Quotienten während des Entwicklungscyclus. Planta 90: 243-266

Senger, H. (1970b). Quantenausbeute und unterschiedliches Verhalten der beiden Photosysteme des Photosyntheseapparates während des Entwicklungsablaufes von Scenedesmus obliquus in Synchronkulturen. Planta 92: $327-346$

Senger, H., Bishop, N. I. (1967). Quantum yield of photosynthesis in synchronous Scenedesmus cultures. Nature, Lond. 214: 140-142

Stross, R. G., Chisholm, S. W., Downing, T. A. (1973). Causes of daily rhythms in photosynthetic rates of phytoplankton. Biol. Bull. mar. biol. Lab., Woods Hole 145: 200-209

Titlyanov, E. A., Kolmakov, P. V., Lee, B. D., Horváth, I. (1978). Functional states of the photosynthetic apparatus of the marine green alga UIva fenestrata during the day. Acta Bot. Acad. Sci. Hung. 24: 167-177

Walther, W. G., Edmunds, L. N. Jr (1973). Studies on the control of the rhythm of photosynthetic capacity in synchronized cultures of Euglena gracilis (Z). Plant Physiol. 51: 250-258

Manuscript first received: November 30,1990

Revised version accepted: May 23, 1991 